\title{
Targeted treatment of recurrent platinum-resistant ovarian cancer: current and emerging therapies
}

This article was published in the following Dove Press journal:

Cancer Management and Research

29 December 2010

Number of times this article has been viewed

\author{
Gina M Mantia-Smaldone' \\ Robert P Edwards ${ }^{2}$ \\ Anda M Vlad ${ }^{3}$ \\ 'Division of Gynecologic Oncology, \\ Hospital of the University of \\ Pennsylvania, Philadelphia, PA, \\ USA; ${ }^{2}$ Division of Gynecologic \\ Oncology, Magee-Womens Hospital \\ of the University of Pittsburgh \\ Medical Center, Pittsburgh, PA, \\ USA; ${ }^{3}$ Department of Obstetrics, \\ Gynecology and Reproductive \\ Sciences, University of Pittsburgh \\ School of Medicine and \\ Magee-Womens Research \\ Institute, Pittsburgh PA, USA
}

Correspondence: Gina M Mantia-Smaldone Division of Gynecologic Oncology, Hospital of the University of Pennsylvania, 3rd floor, PCAM, 34th and Spruce Streets, Philadelphia, PA 19104, USA

$\mathrm{Tel}+\mathrm{I} 2$ 15-662-3327

Fax +l 215-573-5408

Email gina.mantia@uphs.upenn.edu

\begin{abstract}
With advances in surgical techniques and chemotherapeutic agents, mortality rates from epithelial ovarian cancer (EOC) have slightly decreased over the last 30 years. However, EOC still ranks as the most deadly gynecologic cancer with an overall 5 -year survival rate of $45 \%$. Prognosis is especially disappointing for women with platinum-resistant disease, where $80 \%$ of patients will fail to respond to available therapies. Emerging treatment strategies have subsequently focused on targets which are integral to tumor growth and metastasis. In this review, we will focus on those innovative agents currently under investigation in clinical trials.

Keywords: platinum-resistant, ovarian cancer, targeted therapy, immunotherapy, angiogenesis, growth factors
\end{abstract}

\section{Introduction}

With almost 14,000 deaths expected in 2010, epithelial ovarian cancer (EOC) remains the most lethal gynecologic malignancy. ${ }^{1}$ Approximately $75 \%$ of women with EOC present with advanced stage disease (stage III or IV). ${ }^{2}$ Current management of ovarian cancer at initial presentation typically consists of surgical cytoreduction followed by platinum/taxane combination chemotherapy. While $70 \%$ to $80 \%$ of patients with advanced EOC will initially respond to this traditional therapy, more than $60 \%$ will experience a recurrence of disease and $70 \%$ to $90 \%$ will ultimately die of their disease. ${ }^{2}$ Predictors for recurrence include late stage, residual disease, advanced age, histologic grade, poor performance status, clear cell or mucinous histology, and suboptimal normalization of CA125 levels following first-line therapy. ${ }^{3,4}$

Patients with recurrent EOC are characterized by their initial response to platinumbased therapy. ${ }^{5}$ Women who experience recurrences greater than 6 months following a response to platinum-based therapy (ie, platinum-free interval [PFI] $>6$ months) are characterized as having platinum-sensitive disease. ${ }^{6}$ Patients in this category are likely to respond to a platinum-based therapy at the time of relapse and are generally offered a platinum agent or a platinum-containing doublet. ${ }^{7}$ Carboplatin-based combination therapy, especially carboplatin with paclitaxel, is most commonly administered as the first-line therapy for recurrence. ${ }^{8}$ Alternatively, carboplatin combined with gemcitabine or pegylated liposomal doxorubicin can be used, giving similar response and survival rates. ${ }^{9,10}$

Women who experience recurrences within 6 months following an initial response to platinum-based therapy (ie, PFI $<6$ months) or who experience stable disease during platinum-based therapy are characterized as having platinum-resistant ovarian cancer. ${ }^{6}$ 
This group will often also encompass those individuals who experience disease progression during platinum-based therapy (ie, platinum-refractory). ${ }^{11}$ With platinum-resistant disease, the selection of treatment is often made on an individual basis, as treatment for recurrent disease is generally not curable. ${ }^{12}$ Goals of treatment often include controlling the diseaserelated symptoms, limiting treatment-related toxicity, and optimizing quality of life. ${ }^{13}$ Patients with platinum-resistant tumors are typically treated with a single cytotoxic agent that is not cross-resistant with platinum compounds; these options will be briefly discussed below. ${ }^{7}$

Current reports indicate a $20 \%$ response rate with contemporary agents, ${ }^{6}$ emphasizing an absolute need for the development of innovative and effective therapeutic strategies for the management of advanced EOC. In this review we will briefly discuss the traditional chemotherapeutic options for recurrent, platinum-resistant epithelial ovarian cancer and then focus on novel therapeutic strategies currently under investigation.
A MEDLINE search combining the following medical subject terms: "recurrent ovarian cancer, platinum resistant disease and treatment", was performed from 2000 to 2010 in order to identify novel targets for recurrent, platinum-resistant ovarian cancer; only articles written in the English language were included in this review. Ongoing and enrolling clinical trials involving emerging therapeutic agents were subsequently identified by searching the ClinicalTrials.gov registry, abstracts of scientific meetings, and reference lists of included studies. A summary of current clinical trials is presented in Table 1. While the results of many clinical trials are not yet available, we discuss how novel targeted therapies may play a future role in the management of this deadly disease.

\section{Chemotherapy resistance assays}

Chemosensitivity and resistance assays, which utilize molecular and cellular strategies with individual tumor biopsies, aim to customize therapy for women with ovarian

Table I Current clinical trials involving targeted agents in platinum-resistant epithelial ovarian cancer

\begin{tabular}{|c|c|c|c|c|c|}
\hline Process & $\begin{array}{l}\text { Molecular } \\
\text { target }\end{array}$ & Agent & $\begin{array}{l}\text { Trial } \\
\text { phase }\end{array}$ & Additional agents & $\begin{array}{l}\text { ClinicalTrials.gov } \\
\text { identifier }\end{array}$ \\
\hline Anti-tumor immunity & $\mathrm{MUCl}$ & MUCI-KLH vaccine & 1 & Adjuvant QS2I & NCT0000604I \\
\hline \multirow[t]{3}{*}{ Anti-tumor immunity } & Whole & Dendritic cells & II & Ontak & NCT00703I05 \\
\hline & tumor cell & & I & Bevacizumab/cyclophosphamide & NCT0068324I \\
\hline & & & 0 & Daclizumab/bevacizumab & NCTOII320I4 \\
\hline Anti-tumor immunity & $\begin{array}{l}\text { Whole } \\
\text { tumor cell }\end{array}$ & $\begin{array}{l}\text { Adoptive transfer } \\
\text { of T lymphocytes }\end{array}$ & $\mid / I I$ & $\begin{array}{l}\text { tumor lysate-pulsed } \\
\text { dendritic cells }\end{array}$ & NCT00603460 \\
\hline \multirow[t]{5}{*}{ Angiogenesis } & VEGF & Bevacizumab & III & Paclitaxel/topotecan/PLD & NCT009769II \\
\hline & & & II & Gemcitabine & NCT0II3I039 \\
\hline & & & II & PLD & NCT008466I2 \\
\hline & & & II & PLD & NCT00945I39 \\
\hline & & & II & Abraxane & NCT00407563 \\
\hline Angiogenesis & VEGFR-2 & Ramucirumab & II & N/A & NCT0072II62 \\
\hline Angiogenesis & VEGF & $\begin{array}{l}\text { Aflibercept } \\
\text { (VEGF Trap) }\end{array}$ & $\mid / I I$ & Docetaxel & NCT0043650I \\
\hline Angiogenesis & VEGFR2 & Cediranib & III & Carboplatin/paclitaxel & NCT00544973 \\
\hline Angiogenesis & VEGFR2 & Vandetanib & $\mid / / I$ & PLD & NCT00862836 \\
\hline Cellular proliferation & EGFR & & II & Docetaxel & NCT 00872989 \\
\hline Angiogenesis & EGFR & Panitumumab & II & PLD & NCT0086II 20 \\
\hline \multicolumn{6}{|l|}{ Cellular proliferation } \\
\hline Angiogenesis & EGFR & Erlotinib & II & Topotecan & NCT0I003938 \\
\hline \multirow[t]{2}{*}{ Cellular proliferation } & & & II & Bevacizumab & NCT00I 26542 \\
\hline & & & II & Bevacizumab & NCT00696670 \\
\hline \multirow[t]{3}{*}{ Angiogenesis } & VEGFR & Sorafenib & II & Topotecan & NCT0I04789I \\
\hline & PDGFR & & ॥ & Gemcitabine & NCT00096395 \\
\hline & C-Kit & & & & \\
\hline Angiogenesis & PDGFR $\alpha$ & IMC3G3 & II & PLD & NCT009I3835 \\
\hline Folate metabolism & $\mathrm{FR} \alpha$ & MORAb-003 & II & Paclitaxel & NCT00738699 \\
\hline DNA repair & PARP & Veliparib & I & PLD & NCTOII 45430 \\
\hline DNA repair & PARP & Iniparib & II & Gemcitabine & NCT0I033292 \\
\hline
\end{tabular}

Abbreviations: MUCI, mucin I; VEGF, vascular endothelial growth factor; PLD, pegylated liposomal doxorubicin; VEGFR-2, vascular endothelial growth factor receptor 2; N/A, not applicable; EGFR, epidermal growth factor receptor; PDGFR $\alpha$, platelet derived endothelial growth factor receptor alpha; FR $\alpha$, folate receptor alpha; PARP, poly-ADP-ribose polymerase. 
cancer, especially those with recurrent disease. The utility of a chemosensitivity assay in recurrent disease was examined in a prospective randomized control trial of 180 women with platinum-resistant disease. ${ }^{14}$ Response rates $(40.5 \%$ vs $31.5 \%$ ) and median progression-free survival (104 vs 93 days) were greater in women randomized to the sensitivity assay-directed group compared with the physician's choice arm. While overall survival was similar between groups, the authors suggest that chemosensitivity testing may provide useful information in select patients. Several national organizations, including the American Society of Clinical Oncology, have released statements to help direct clinical use of these assays; at this time, there are not enough reliable data to recommend the use of these assays in clinical practice. ${ }^{15}$ Future studies focusing on the utility and cost benefits of these assays in platinum-resistant disease may help to clarify their impact on patients' outcomes.

\section{Chemotherapy use in platinum-resistant disease}

Nonplatinum-based single-agent chemotherapy is considered first-line therapy in the treatment of recurrent, platinumresistant EOC. Commonly utilized agents include pegylated liposomal doxorubicin, paclitaxel, gemcitabine, topotecan, docetaxel, and etoposide, with response rates ranging from $10 \%$ to $30 \%$. ${ }^{6}$ Often the choice of agent is driven by its side effect profile, administration, and availability.

Pegylated liposomal doxorubicin (PLD), a DNA intercalating agent with reported objective response rates (ORRs) as high as $26 \%$, is commonly administered as the first-choice nonplatinum reagent for recurrent platinumresistant disease. ${ }^{16,17}$ Due to its adverse events, the most significant of which is palmar-plantar erythrodysesthesia (hand-foot syndrome), PLD is currently being evaluated as a component of combination therapy. ${ }^{18}$

Paclitaxel, a microtubule inhibitor, has produced ORRs up to $30 \%$ in women with platinum-resistant EOC, ${ }^{5}$ and combination paclitaxel and carboplatin therapy has also demonstrated objective clinical benefits. ${ }^{19}$ Common adverse events with paclitaxel include neurotoxicity and myelosuppression, events that can be potentially improved with different dosing schedules. Through a similar mechanism, docetaxel has demonstrated activity in cases of platinum-resistant disease but with reduced efficacy and increased patient toxicity. ${ }^{20}$

Single-agent gemcitabine, a nucleoside pyrimidine analog, has a reported ORR of $16 \%$ in platinum- and paclitaxel-refractory disease. ${ }^{21}$ While myelosuppression is a common dose-limiting toxicity, gemcitabine may be an acceptable alternative to PLD given similar response rates and progression-free survival in a recent phase III study. ${ }^{22}$

Topoisomerase inhibitors utilized in platinum-resistant patients include topotecan and etoposide. While respective response rates of $12 \%$ to $14 \%{ }^{23}$ and $26.8 \%{ }^{24}$ with topotecan have been reported, dosing is limited by hematotoxicity. In a phase II Gynecologic Oncology Group (GOG) study, Rose et al reported a response rate of $32 \%$ with etoposide in platinum and paclitaxel resistant patients. $^{25}$

Second-line agents for platinum-resistant disease include irinotecan, vinorelbine, ifosfamide, and leucovorinmodulated 5-fluorouracil. In a single-institution phase II trial, irinotecan, a topoisomerase inhibitor, produced a response rate of $17.2 \%$ in 31 patients with platinum-resistant/refractory EOC or primary peritoneal cancer (PPC) with acceptable toxicity. ${ }^{26}$ Vinorelbine, an antimicrotubule agent, has demonstrated a response rate of $21 \%$ in a recent phase II trial. ${ }^{27}$ Ifosfamide, an alkylating agent, produced a response rate of $12 \%$ in a phase II trial of 41 patients with platinum-resistant disease, the most common reported toxicities including myelosuppression, nephrotoxicity, and central nervous dysfunction. ${ }^{28}$ 5-Fluorouracil, a pyrimidine analog, although well tolerated, produced a response rate of only $18 \%$ in a recent retrospective report. ${ }^{29}$

\section{Novel cytotoxic therapies}

Emerging cytotoxic agents are currently being introduced into the management of platinum-resistant ovarian cancer. These include chemotherapeutic compounds classified in drug categories with known activity in EOC, including taxanes (eg, paclitaxel poliglumex), anthracyclines (eg, sabarubicin), alkylating agents (eg, canfosfamide), and topoisomerase inhibitors (eg, rubitecan), or novel drug categories, such as epothilones (eg, ixabepilone, patupilone).

Ixabepilone belongs to a new class of agents, epothilones, which act to stabilize microtubules. While mechanistically similar to taxanes, epothilones are structurally unrelated and may circumvent mechanisms in taxane resistance. ${ }^{30}$ In a phase II GOG trial, ixabepilone produced an ORR of $14.3 \%$ in 49 women with platinum- and taxane-resistant EOC or PPC. ${ }^{31}$ Clinical trials with ixabepilone monotherapy (NCT00025155, NCT00030706) and combination therapy with pegylated liposomal doxorubicin (NCT00182767) are currently accruing.

Trabectedin is an anti-tumor agent which binds to DNA and interferes with DNA repair, thereby blocking cell cycle progression. ${ }^{32}$ In a multicenter phase II trial, trabectedin monotherapy was active in platinum-resistant EOC with 
an ORR of $6.3 \% .{ }^{33}$ Trabectedin in combination with PLD was recently evaluated in a randomized phase III trial with platinum-sensitive and -resistant recurrent disease. ${ }^{18}$ While the response rate was significantly higher in women with platinum-sensitive disease receiving combination therapy vs PLD monotherapy (35.3\% vs $22.6 \%, P=0.004)$, ORRs were not statistically different between treatment arms in the platinum-resistant population.

Pemetrexed is a folate antimetabolite which inhibits a number of enzymes critical to nucleotide synthesis. ${ }^{34}$ In a phase II GOG trial, pemetrexed monotherapy was administered to 48 women with platinum-resistant EOC or PPC, reporting an ORR of $21 \%$ with median progressionfree and overall survivals of 2.9 months and 11.4 months, respectively. ${ }^{35}$

Phenoxodiol promotes Fas-mediated apoptosis by activating the mitochondrial caspase system, inhibiting the X-linked inhibitor of apoptosis and disrupting FLICE inhibitory protein (FLIP) expression. ${ }^{36}$ In vitro and preclinical animal studies indicate that phenoxodiol can sensitize EOC cells to carboplatin, paclitaxel, and gemcitabine, ${ }^{37}$ and phenoxodiol combination therapies including carboplatin, paclitaxel, and docetaxel are currently being evaluated.

Third-generation platinum agents, including oxaliplatin, satraplatin, and picoplatin, have incomplete cross-resistance with either cisplatin or carboplatin and have subsequently been shown to have minor activity in platinum-resistant disease. In a phase II GOG trial, single-agent oxaliplatin produced an ORR of $4.3 \%$ in 23 women with platinumresistant or -refractory EOC, ${ }^{38}$ which has led to investigation of oxaliplatin in combination with 5-fluoruracil/leucovorin, ${ }^{39}$ paclitaxel, ${ }^{40} \mathrm{PLD},{ }^{41}$ and gemcitabine. ${ }^{42}$ Satraplatin is an orally administered platinum agent with in vitro activity against platinum-resistant ovarian cancer cell lines $;{ }^{43}$ however, these findings have not yet been confirmed in clinical trials. Picoplatin is currently under investigation in a phase I trial of patients with advanced solid tumors, including ovarian cancer (NCT00465725).

\section{Emerging approaches to platinum-resistant EOC}

In addition to novel cytotoxic agents, targeted molecular strategies have been employed in the treatment of recurrent, platinum-resistant ovarian cancer. These strategies attempt to manipulate processes critical to ovarian carcinogenesis, including cellular growth and proliferation, cellular adhesion, intracellular signaling pathways, angiogenesis, and DNA repair pathways. ${ }^{44}$ In the following section, we will focus on emerging agents targeting host-tumor immune responses, intracellular signaling pathways, cellular adhesion molecules, endocrine pathways, and DNA repair mechanisms.

\section{Immunotherapy}

Effective host anti-tumor immune responses have the potential to influence prognosis in patients with EOC. The presence of tumor-infiltrating lymphocytes (TILs) has been correlated with significantly improved progression-free and overall survival rates in women with advanced stage EOC. ${ }^{45}$ Further, the presence of CD4+CD25+FOXP3+ T regulatory (Treg) cells in tumors has a reported negative impact on survival, suggesting that these cells might suppress host anti-tumor immunity. ${ }^{46,47}$ Thus, by manipulating the host immune system, it may be possible to enhance host antitumor immune responses and improve patient outcomes, especially in those with platinum-resistant disease. Current immunotherapeutic approaches employ either vaccines based on tumor-associated antigens (TAA), antitumor cytokines, or antibodies targeting co-stimulatory and immunosuppressive molecules. ${ }^{48}$

\section{Tumor antigens}

Several proteins that are abnormally expressed in cancer cells, due to mutations, overexpression, or post-translational modifications, have been identified and are currently studied as targets for immunotherapy. In a recent analysis from the National Cancer Institute Pilot Project for the acceleration of translational research, 75 tumor antigens were priority ranked for cancer vaccine development. ${ }^{49}$ Some of these antigens, including MUC1, CA125, human epidermal growth factor receptor 2 (HER2)/neu, membrane folate receptor, TAG-72, mesothelin, and NY-ESO-1, are targets of therapeutic tumor vaccines in ovarian cancer. ${ }^{48}$

Due to its oncogenic properties, immunogenicity and expression pattern, MUC1 received the second highest priority ranking, after $\mathrm{WT} 1 .{ }^{49} \mathrm{MUC} 1$ is a transmembrane mucin overexpressed in more than $90 \%$ of epithelial ovarian cancers, including platinum-resistant tumors. ${ }^{50,51}$ Thus, MUC1 has been often studied as a target for antibody-based immunotherapy. A phase I trial using a murine anti-MUC1 antibody (HMFG1) was conducted in 26 patients with persistent/recurrent ovarian cancer following platinum-based chemotherapy. ${ }^{51}$ While no clinical responses were appreciated, anti-HMFG1 and anti-MUC1 antibody responses were significantly elevated in those individuals completing the vaccination regimen. In a phase I/II trial, 52 women received intraperitoneal (IP) injections of a radioactively-labeled 
form of this antibody, yttrium-90-muHMFG1, following traditional surgery and platinum-based chemotherapy with improved median survival rates compared with historical controls. ${ }^{50}$ While a subsequent phase III trial failed to show a survival benefit with IP administration of yttrium-90-muHMFG1 as consolidation treatment, the authors reported a significant decrease in IP recurrences in the treatment group. ${ }^{52}$ Unfortunately, this finding was offset by increased extraperitoneal recurrences. In addition to MUC1-specific antibodies, vaccines based on MUC1 peptides designed to trigger $\mathrm{T}$ cell immunity have been proposed in ovarian cancer (NCT00006041).

CA125 (MUC16), another member of the mucin family, is a marker utilized to monitor response to chemotherapy and to survey for disease recurrence. Approximately $80 \%$ of ovarian cancer tumors are CA125 positive, suggesting that immunotherapy targeting this TAA may be of clinical relevance. ${ }^{53}$ Monoclonal antibodies to CA125 (B43.13, oregovomab) have been utilized in phase II and III trials of patients with recurrent disease. ${ }^{53,54}$ In the first trial, oregovomab was administered to 13 heavily pretreated, recurrent ovarian cancer patients, including 6 women with platinumresistant disease..$^{53}$ Oregovomab and CA125 antibody and T cell specific responses were reported in greater than $50 \%$ of the patients. While there were no objective responses, $23 \%$ of patients experienced stabilization of disease and survival greater than 2 years, and these clinical responses corresponded with robust immune responses to treatment..$^{53} \mathrm{In}$ the latter trial, 20 patients with advanced recurrent ovarian cancer (and with a history of platinum exposure) received oregovomab followed by optional chemotherapy. ${ }^{54}$ Anti-CA125 antibodies were produced in $2(11 \%)$ patients, while 15 (79\%) of patients developed human anti-mouse antibodies (HAMAs) and anti-oregovomab antibodies. Overall median survival and progression-free survival was 70.4 weeks (4.6 to 14.6 weeks) and 11 weeks (2.6 to 114.6 weeks), respectively. T cell responses specific to CA125 and/or autologous tumor were significantly associated with improved survival $(P=0.002)$.

Anti-idiotypic antibodies to CA125 (ACA125, abagovomab) have also been utilized in clinical trials..$^{55,56}$ Generated against primary anti-CA125 antibodies, these antibodies can serve as surrogate antigens given that they imitate the antigen of interest, and it has been postulated that vaccination with anti-idiotypic antibodies can increase host responses. ${ }^{48}$ In a phase I/II trial, abagovomab was administered to 119 patients with advanced ovarian cancer, including 44 patients with platinum-resistant disease. ${ }^{56}$ Antibodies to ACA125 and CA125 were generated in $68 \%$ and $50 \%$ of patients, respectively, and antibody-dependent cell-mediated cytotoxicity (ADCC) of CA125-positive cancer cells was demonstrated in 27\% of patients. Individuals with anti-ACA125 antibodies had a significantly longer survival compared to those without such a response (median, 23.4 months vs 4.9 months; $P<0.0001$ ). Two additional studies demonstrated the presence of antiabagovomab antibodies in all evaluable patients, but these responses were not assessed for association with survival benefit due to study design. ${ }^{55,57}$

\section{Cytokine therapy}

Proinflammatory cytokines, including interleukins (IL) 2, 4, 7, 12 and 18, interferon gamma (IFN- $\gamma$ ), tumor necrosis factor alpha (TNF- $\alpha$ ), and granulocyte-macrophase colony-stimulating factor (GM-CSF), have been utilized in preclinical models to induce anti-tumor immune responses..$^{58}$ In a phase II trial in patients with platinum-resistant and refractory EOC, IP IL-2 therapy resulted in an overall response rate of $25 \%$ with a median survival time of 2.1 years. ${ }^{59}$ The authors also reported a significant association between patient survival and changes in $\mathrm{CD} 3 \mathrm{~T}$ cells and IFN- $\gamma$ producing CD8 $\mathrm{T}$ cell counts at early treatment time points, suggesting that anti-tumor responses may be critical to prognosis.

GM-CSF alone and in combination with recombinant IFN- $\gamma 1 \mathrm{~b}(\mathrm{rIFN}-\boldsymbol{\gamma} 1 \mathrm{~b})$ has recently been incorporated into phase II trials. ${ }^{60,61}$ Roche et al used single agent GM-CSF in 72 women with asymptomatic recurrent müllerian malignancy without an indication for immediate systemic chemotherapy. ${ }^{60}$ While 1 patient experienced a complete response and 20 patients experienced stable disease following treatment, $70 \%$ of women experienced a drop in CA125 levels from baseline. GM-CSF in combination with rIFN- $\gamma 1 \mathrm{~b}$ and carboplatin produced a response rate of $56 \%$ in a cohort of 59 patients with recurrent, platinum-sensitive ovarian, fallopian tube and PPC. ${ }^{61}$ Given these encouraging results, further studies examining efficacy in platinum-resistant disease are necessary.

IFN- $\gamma$ induced upregulation of major histocompatibility complex molecular expression on antigen presenting cells, including dendritic cells, macrophages and B cells, can enhance host immune responses via activation of $\mathrm{T}$ cellmediated pathways. ${ }^{62}$ Preclinical evaluation of a CD80 (B7-1)/ IFN- $\gamma$ modified vaccine showed enhancement of tumorspecific cytotoxic activity, resulting in reduction of tumor growth.$^{63}$ However, this vaccine has not yet been attempted in clinical trials with platinum-resistant disease. 


\section{Other immune strategies}

In addition to TAA and recombinant cytokine therapies mentioned above, vaccine-approaches in EOC have also utilized whole tumor cell lysates and dendritic cells in an attempt to boost host anti-tumor immune responses. The former affords the opportunity for broad tumor antigen exposure, while use of dendritic cells (DCs) enhances anti-tumor immunity via specific tumor-antigen presentation and activation of effector T cells. ${ }^{44}$ The first and currently only Food and Drug Administration approved cancer therapeutic vaccine is the DC-based Provenge ${ }^{\circledR}$ vaccine (Dendreon Corporation, Seattle, WA) administered as autologous cellular therapy in castrate-resistant prostate cancer. ${ }^{64}$ The value of Provenge in triggering effective immunity against other cancer types, including ovarian cancer, remains to be established.

DC-based immunotherapy in ovarian cancer has focused on several approaches, including exposure (also known as pulsing) of DCs to whole cell tumor lysates, defined ovarian tumor peptides, and ovarian tumor cells, to induce a cytotoxic T lymphocyte (CTL) response ${ }^{65}$ In a pilot study, autologous DCs were pulsed with HER-2/neu or MUC1-derived peptides and administered to 10 patients with advanced breast or ovarian cancer. ${ }^{66}$ Half of the patients experienced peptide-specific CTL responses, but unfortunately these responses were not correlated with long-term outcomes. In a phase I trial, autologous tumor antigen-pulsed DCs were administered to 6 patients with progressive or recurrent ovarian cancer. ${ }^{67}$ Half of the patients experienced stabilization of disease with progression-free intervals of 8 to 45 months, and lymphoproliferative responses were reported in 2 patients. Given these promising data, DC-based immunotherapy is currently the focus of several new trials (NCT00703105, NCT00683241, and NCT01132014) which will hopefully demonstrate an impact on long-term prognosis.

Adoptive immunity is a process by which immune cells, including T lymphocytes, B lymphocytes, natural killer cells, and macrophages, are removed from an individual, modified extracorporeally and then placed back into the same individual. ${ }^{68}$ The adoptive transfer of autologous TILs has proven to be quite effective in metastatic melanoma patients, with reported ORRs of greater than $50 \% .{ }^{69}$ The same process was met with high response rates in a sample of women with advanced or recurrent EOC, ${ }^{70}$ and subsequent studies in ovarian cancer have examined the utility of adoptive transfer with modified $\mathrm{T}$ cells to enhance antitumor activity. ${ }^{71,72} \mathrm{~A}$ phase I/II trial has been proposed in which patients with recurrent EOC or PPC will undergo adoptive transfer of ex vivo CD3/ CD28-costimulated autologous peripheral blood $\mathrm{T}$ cells along with tumor lysate-pulsed DCs (DCVax ${ }^{\circledR}$-L; Northwest Biotherapeutics, Inc., Bethesda, MD) (NCT00603460) in order to determine the feasibility and safety of this combination and progression-free survival at 6 months.

In addition, investigations have begun focusing on molecules (eg, cytotoxic T lymphocyte-associated antigen 4, CTLA-4) $)^{73}$ and cell populations (Tregs) ${ }^{74}$ which suppress host immune responses. These trials will hopefully reinforce the utility of these novel immunotherapeutic techniques in the treatment of recurrent EOC and lay the foundation for studies specific to platinum-resistant disease.

\section{Tyrosine kinase receptors and intracellular signaling pathways}

Angiogenesis is critical to tumor growth/metastasis and several proangiogenic factors, including vascular endothelial growth factor (VEGF), IL-8, platelet-derived endothelial cell growth factor (PDGF), angiogenin, and fibroblast growth factor (FGF), have been implicated in tumorigenesis. ${ }^{75}$ Molecules, including VEGF, epidermal growth factor receptor (EGFR), and PDGF among numerous others, play critical roles in processes that support cancer growth and metastasis, and several tyrosine kinase receptors and intracellular signaling pathways are currently under review for ovarian cancer targeted therapy. Of these molecules, VEGF has been the most commonly studied, given that it is abundantly present in the serum of patients with EOC, ${ }^{76,77}$ and that elevated VEGF levels have been associated with poor survival. ${ }^{78}$

Bevacizumab is a humanized monoclonal antibody which interferes with the binding of VEGF-A to its receptor. Bevacizumab has been utilized as monotherapy or in combination in several clinical trials, where its efficacy and safety have been demonstrated. ${ }^{79,80}$ GOG-170D was a phase II trial in which single-agent bevacizumab was administered intravenously to 62 women with persistent or recurrent EOC or PPC (41.9\% with platinum-resistant disease) to assess efficacy and tolerability. ${ }^{79}$ Clinical responses were observed in $21 \%$ of patients, and median progression-free and overall survivals were 4.7 and 17 months, respectively. Bevacizumab was well tolerated in this sample, suggesting it may serve as an effective second- or third-line option for patients with EOC/PPC.

Cannistra et al investigated the use of bevacizumab monotherapy in a sample of 44 women with platinum-resistant EOC or PPC who had experienced disease progression during or within 3 months of discontinuing topotecan or liposomal doxorubicin. ${ }^{80}$ Seven patients $(15.9 \%)$ experienced partial responses; median progression-free and overall survival 
were 4.4 and 10.7 months, respectively, at study conclusion. However, enrollment was closed early in this study due to a higher than expected rate of gastrointestinal perforation (GIP, 11.4\%). GIP was significantly associated with increased number of prior chemotherapy regimens, suggesting this adverse event may be due to the advanced disease status in this patient sample. This study suggests that bevacizumab monotherapy may play a role in the treatment of patients with heavily pretreated, platinum-resistant EOC although further prospective evaluation is warranted.

Bevacizumab in combination with taxanes and cyclophosphamide has also been investigated in women with recurrent EOC. ${ }^{81,82}$ In a phase II trial evaluating bevacizumab and cyclophosphamide therapy in 70 patients, $24 \%$ of patients experienced a partial response to therapy and median progression-free and overall survival were 7.2 and 16.9 months respectively. ${ }^{82}$ The results of a recently completed phase II trial of weekly topotecan with bevacizumab in women with platinum-resistant EOC, fallopian tube cancer, or PPC (NCT00343044) are also currently pending. Other bevacizumab combination regimens including paclitaxel, topotecan, or liposomal doxorubicin (NCT00976911, NCT01131039, NCT00846612, NCT00945139, NCT00407563) are currently in the evaluation process. The results of these trials will certainly generate considerable interest and may potentially impact treatment for recurrent, platinum-resistant disease.

Ramucirumab (IMC-1121B), which blocks VEGFR-2 on tumor endothelial cells, is another human monoclonal antibody targeting the VEGF pathway. ${ }^{83}$ The safety and tolerability of this antibody have been demonstrated by a nearcompleted phase I trial, ${ }^{83}$ while a nonrandomized phase II trial (NCT00721162) is investigating ramucirumab monotherapy in platinum-refractory persistent or recurrent EOC, PPC, or fallopian tube cancer to assess efficacy. ${ }^{84}$

VEGF Trap (aflibercept) is a recombinant fusion protein which combines the VEGF binding domains of VEGFR1 and VEGFR2 with the Fc region of immunoglobulin (IgG1) and acts as a soluble decoy receptor by binding to VEGF. ${ }^{85}$ In a randomized phase II trial, 11\% of patients with recurrent, platinum-resistant disease achieved objective responses with VEGF Trap, ${ }^{86}$ and VEGF Trap combined with docetaxel is currently under investigation in a phase I/II trial of patients with persistent or recurrent EOC, PPC, or fallopian tube cancer (NCT00436501).

Small molecule receptor tyrosine kinase inhibitors (TKIs) targeting the VEGF pathway are also being examined. Cediranib, a competitive inhibitor of VEGFR2, is currently under investigation in the ICON 6 trial. In this randomized, phase III trial, cediranib with carboplatin/paclitaxel chemotherapy is being compared to carboplatin/paclitaxel alone in a sample of women with recurrent, mostly platinumsensitive, EOC utilizing overall survival as the primary end point. ${ }^{87}$ Vandetanib is another TKI which interferes with both VEGFR2 and EGFR, resulting in its antiangiogenesis and antiproliferative activity. Combination regimens with vandetanib and liposomal doxorubicin (NCT00862836) and docetaxel (NCT 00872989) are currently under investigation in phase I and/or II trials.

EGFR (ErbB1, HER1), ErbB2 (HER2), ErbB3, and ErbB4 are 4 tyrosine kinase receptors which comprise the EGFR receptor family ${ }^{88}$ Following ligand binding, these receptors undergo dimerization, internalization of the ligand-receptor complex, and finally tyrosine auto-phosphorylation. ${ }^{85} \mathrm{Via}$ downstream targets such as PI3K/Akt and MAPK, activation of EGFR receptors ultimately leads to cellular proliferation, differentiation, metastasis, and angiogenesis. ${ }^{89}$ As a result, monoclonal antibodies have been created to inhibit these EGFR-dependent pathways, most notably EGFR and ErbB2 (HER2). Cetuximab and panitumumab are mouse/human chimeric and human monoclonal antibodies, respectively, which target EGFR. Trastuzumab and pertuzumab are monoclonal antibodies which target ErbB2/HER2.

In a phase II trial, cetuximab monotherapy was administered to 25 women with persistent or recurrent EOC or PPC (64\% with platinum-resistant disease) in order to determine its safety and efficacy. ${ }^{90}$ Only 1 patient (4\%) with platinumresistant EOC experienced an objective partial response; this trial was subsequently terminated due to poor response rate. While all patient tumors expressed EGFR, the authors postulated that future investigation should focus on determining which subcohort of patients would directly benefit from therapy. Panitumumab is a monoclonal antibody which has been studied in EGFR-expressing metastatic colorectal cancer. ${ }^{91}$ Panitumumab in combination with PLD is currently under investigation in a phase II trial with platinum-resistant, KRAS wild-type EOC patients (NCT00861120).

After demonstrating the ability to prolong disease-free and overall survival in breast cancer, trastuzamab, a monoclonal antibody that interferes with the HER2 receptor, has been approved for use as an adjuvant therapy in patients with HER2-positive breast cancer. ${ }^{92}$ HER2 expression is negatively correlated to survival in ovarian cancer patients. ${ }^{93}$ In a phase II GOG trial, trastuzumab was administered as a single agent to 41 women with HER2-positive, recurrent, or persistent EOC or PPC. ${ }^{4}$ There was an overall response rate of $7.3 \%$ with a median progression-free survival of 
2.0 months, suggesting that the overall potential therapeutic benefit for trastuzamab in EOC may be limited.

Pertuzumab, a monoclonal antibody referred to as a "HER dimerization inhibitor", is currently being evaluated in patients with HER2-positive EOC due to the ability to prevent activation of HER2 downstream pathways. ${ }^{85}$ In a randomized controlled phase II trial of 130 women with platinum-resistant EOC/fallopian tube cancer/PPC, women who had received pertuzumab and gemcitabine had better ORRs (13.8\% vs $4.6 \%$ for placebo group) and a trend towards improved progression-free survival (hazard ratio $0.66, P=0.07$ ) when compared to a sample receiving gemcitabine and placebo. ${ }^{95}$ While these findings were nonsignificant, the authors suggest that with further study pertuzumab may be an effective agent for the treatment of platinum-resistant disease.

TKIs targeting the EGFR family, including gefitinib and erlotinib, are currently under evaluation. In a phase II GOG trial, gefitinib was administered to a group of 27 women with recurrent or persistent EOC or PPC, consisting of $37 \%$ and $63 \%$ with platinum-sensitive and -resistant disease, respectively. ${ }^{96}$ Only 1 patient (4\%) experienced an objective response to treatment; however, women in this trial were not prescreened for EGFR mutations which the authors argue may improve response rates to gefitinib. These results were further substantiated in a phase II trial in which there were no objective responses to gefitinib monotherapy in women with heavily pretreated, recurrent EOC who had detectable levels of EGFR (both total and a phosphorylated form) ${ }^{97}$ In a recent phase II trial, erlotinib and carboplatin combination therapy was more active in sensitive than -resistant disease. ${ }^{98}$ Trials combining erlotinib with topotecan (NCT01003938) and with bevacizumab (NCT00126542, NCT00696670) are currently under way.

In addition to EGFR, investigations have focused on other growth factor receptors critical to the angiogenesis pathway. Platelet-derived growth factor receptor (PDGFR), a tyrosine kinase receptor which enhances cellular proliferation, is present in $50 \%$ to $80 \%$ of ovarian cancers. ${ }^{99}$ TKIs targeting PDGFR, including imatinib, sorafenib, sunitinib, and pazopanib, are presently under review in recurrent EOC. Imatinib, a TKI with activity against Abl, PDGFR, and c-kit, has minimal activity in platinum-resistant disease, as highlighted by 2 recent phase II trials. ${ }^{100,101}$ Sorafenib, which targets VEGFR, PDGFR, and c-kit, is currently being examined in combination with topotecan (NCT01047891) and gemcitabine (NCT00096395). Treatment with sunitinib, which targets VEGFR and PDGFR, produced no objective responses in a phase II trial of women with recurrent ovarian cancer. ${ }^{102}$ Pazopanib, a TKI targeting VEGFR, PDGFR, and c-kit, has produced an ORR of $18 \%$ in a phase II trial with 36 recurrent EOC patients, including 9 with platinum-refractory and -resistant disease. ${ }^{103}$ In addition to small molecule TKIs, a monoclonal antibody, IMC 3G3, has been introduced which inhibits the PDGFR $\alpha$; this antibody combined with PLD is currently under review in a phase II trial of platinum-resistant EOC patients (NCT00913835).

Aurora kinases and members of the hedgehog and PI3K/ AKT/mTOR signaling pathways have also been examined as novel targets for recurrent EOC therapy; the results of several phase II trials involving these agents are currently pending.

\section{Folate metabolism}

Folate receptor-alpha (FR $\alpha$ ) is a glycosyl-phosphatidylinositol-linked member of the folate receptor family which is overexpressed in the majority of nonmucinous EOCs. ${ }^{104,105}$ FR $\alpha$ binds folic acid with high affinity, permitting cancer cells to grow in low folate concentrations and thereby facilitating DNA synthesis. ${ }^{106}$ Three anti-human FR $\alpha$ monoclonal antibodies have been studied in clinical trials: MOV18, murine LK26 and MORAb-003. MOV18 is a murine or chimeric anti-FR monoclonal antibody which had been administered to women with ovarian cancer in phase I trials and suggested a clinical benefit with minimal toxicity. ${ }^{107,108}$ More recently, this antibody has been investigated in radioimmunotherapy preclinical studies. ${ }^{109,110}$ LK26 is another murine anti-FR antibody which had been investigated in preclinical trials but was never studied in clinical trials due to its decreased affinity for the FR following humanization of the antibody. ${ }^{111}$ MORAb-003, a humanized anti-FR monoclonal antibody, was subsequently derived by optimizing the LK26 molecule. MORAb-003 has been studied in phase I and II trials; ${ }^{112,113}$ preliminary results suggest that this molecule is safe and efficacious in the treatment of EOC. The utility of this molecule in treating platinum-resistant disease will hopefully be determined by a randomized, double-blinded, placebo-control study examining paclitaxel with and without concurrent MORAb-003 (NCT00738699).

\section{Cellular adhesion}

Cellular adhesion molecules, including epithelial celladhesion molecule (EpCAM), mesothelin, and integrin, may play critical roles in tumor metastasis and are currently molecular targets in recurrent EOC. EpCAM is an antigen expressed in the majority of epithelial cancers, ${ }^{114}$ and is significantly overexpressed in recurrent EOC when 
compared with normal ovarian tissue and with primary ovarian carcinomas. ${ }^{115}$ Further, EpCAM is highly expressed on the surface of chemotherapy-resistant ovarian cancer cell lines. ${ }^{115}$ EpCAM is thus a molecule which can facilitate targeted immunotherapy in the local tumor microenvironment, especially for those women with recurrent and chemotherapy resistant disease. Catumaxomab is a trifunctional antibody with 2 antigen-binding sites, targeting EpCAM on epithelial tumor cells and CD3 on T cells, with a functional Fc domain. ${ }^{116}$ Thus, this antibody functions to recruit and activate immune effector cells at the tumor site. In a randomized, 2-arm phase II/III trial, IP catumaxomab in combination with paracentesis was compared with paracentesis alone in 258 patients with recurrent, symptomatic malignant ascites, including 129 patients with primary ovarian cancer. ${ }^{117}$ In the ovarian cancer patients, median puncture-free survival and time to next paracentesis were both significantly prolonged in the combination group compared with the paracentesis alone group, suggesting that catumaxomab provides a clinical benefit to those women with EOC-related malignant ascites.

Mesothelin is overexpressed on ovarian cancer cell membranes and is believed to be involved in cellular adhesion. ${ }^{118}$ An anti-mesothelin immunotoxin, SS1P, has recently been examined in phase I trials of mesothelin-expressing tumors and while clinical activity has been suggested, these findings need to be further confirmed. ${ }^{118}$ Integrins are receptors that are important in cellular adhesion; a monoclonal antibody to alpha(v)-integrins is currently under investigation in phase I trials.

\section{Hormonal therapy}

Hormones, particularly estrogen and progesterone, play key roles in ovarian carcinogenesis. This association is probably best highlighted by the fact that oral contraceptive pill use decreases the incidence of ovarian cancer. ${ }^{119}$ Further, estrogen and progesterone receptors are often present on ovarian cancer cells, and in vitro responses have been reported to tamoxifen and other hormonal agents. ${ }^{120}$ Unlike in breast cancer, hormone-driven therapy has not been met with success in the treatment of platinum-resistant EOC.

Selective estrogen receptor modulators, specifically tamoxifen, have been investigated in the treatment of platinum-resistant disease. In a recent Cochrane review, the role of tamoxifen in recurrent EOC could not be established due to a lack of comparative studies. ${ }^{121}$ However, when analyzing noncomparative studies, an overall ORR of $9.6 \%$ was determined, with individual studies reporting ranges from $0 \%$ to $56 \%$. Aromatase inhibitors inhibit the conversion of androgens into estrogens via the aromatase enzyme. These agents, particularly letrozole, have also been studied in the treatment of platinum-resistant EOC. In a single-institution, phase II trial, letrozole produced an ORR of $3 \%$ in a sample of patients with platinum- and taxaneresistant, estrogen-receptor positive recurrent EOC or PPC and $74 \%$ of patients experienced disease progression. ${ }^{122}$ Furthermore, an ORR of 9\% was appreciated in a sample of 42 women with estrogen-positive relapsed EOC, of which $43 \%$ of individuals had platinum-resistant disease. ${ }^{123}$ Fulvestrant is a novel estrogen receptor antagonist which does not possess any agonistic effects. In a single-institution, phase II trial, fulvestrant produced no objective responses by modified RECIST criteria in a sample of 26 heavily pretreated EOC patients but did stabilize disease in $35 \%$ of patients. ${ }^{124}$ No further studies are currently available which focus on the use of this agent specifically in platinum-resistant disease. Mifepristone is a competitive progesterone receptor antagonist which has recently been studied in platinumresistant EOC. In a phase II GOG trial, mifepristone was administered to patients with recurrent or persistent EOC, fallopian tube cancer, or PPC. ${ }^{125}$ While it is unclear how many patients had platinum-resistant disease, only 1 patient experienced an objective response, suggesting that this agent is likely not effective in this patient sample. No additional studies have been reported. GnRH analogs have also been investigated in platinum-resistant EOC. In a sample of 12 patients with platinum-resistant disease, leuprolide produced an ORR of $8.3 \%$; however, $66.7 \%$ patients experienced disease progression. ${ }^{126}$ In a nonrandomized, phase II trial, goserelin in combination with tamoxifen was administered to 26 patients with recurrent EOC, including 65\% with platinum-resistant disease. ${ }^{127}$ While authors suggest that $50 \%$ of patients experienced a clinical benefit, objective responses were experienced in only 3 patients $(11.5 \%)$. A luteinizing hormone-releasing hormone antagonist, cetrorelix, has also been shown to modest activity in a cohort of patients with platinum-resistant disease. ${ }^{128}$

\section{DNA repair pathways}

BRCA 1 and 2 are two proteins that play critical roles in homologous recombination, a process that repairs doublestranded DNA breaks. ${ }^{129}$ Germline mutations in BRCA 1 and 2 are present in up to $15 \%$ of women afflicted with ovarian cancer. ${ }^{130}$ Inhibition of an additional DNA repair pathway, specifically base excision repair (BER), has been shown to be a lethal event in BRCA dysfunctional cells, a term commonly referred to as synthetic lethality. ${ }^{131}$ 
Poly-ADP-ribose polymerase (PARP) is a nuclear enzyme which participates in BER and has been a current target of therapy in BRCA dysfunctional patients. While initial investigation has focused on the use of PARP inhibitors in individuals with germline mutations, a recent report suggests that additional EOC patients with somatic BRCA 1 or 2 dysfunction, a phenotype referred to as "BRCAness", may also benefit from this novel drug class. ${ }^{132}$ Olaparib is the most studied PARP inhibitor in women with EOC. In a multicenter, international phase II trial, $100 \mathrm{mg}$ and $400 \mathrm{mg}$ doses of olaparib were administered to women with BRCA 1 or 2 germline mutations who had recurrent EOC, fallopian tube cancer, or PPC; ${ }^{133}$ the trial included women with both platinum-sensitive and -resistant disease. ORRs were appreciated in $33 \%$ of patients receiving the $400 \mathrm{mg}$ twice daily dose and $13 \%$ of patients receiving the $100 \mathrm{mg}$ twice daily dose. Further, women with platinumsensitive and -resistant disease experienced ORRs of $38 \%$ and $30 \%$, respectively, with the $400 \mathrm{mg}$ dosing regimen. These encouraging results suggest that olaparib may be an efficacious and safe treatment option in BRCA-mutated advanced ovarian cancer.

Other PARP inhibitors, including veliparib, iniparib (BSI 201), and AG014699, are currently under investigation as monotherapy or in combination with other chemotherapeutic agents in women with recurrent ovarian cancer. Veliparib in combination with pegylated liposomal doxorubicin is being studied in a phase I trial of women with recurrent EOC, fallopian tube cancer, PPC, or metastatic breast cancer (NCT01145430). Iniparib in combination with carboplatin and gemcitabine is currently being studied in resistant ovarian cancer patients (NCT01033292). The results of these studies will certainly help to determine the role of PARP inhibitors in the treatment of recurrent ovarian cancers, including those with BRCA germline and somatic dysfunction.

\section{Conclusion}

Current available treatments for platinum-resistant ovarian cancer generally produce modest response rates approaching $20 \%$, which indicates significant room for improvement. In addition to novel cytotoxic agents, emerging approaches based on small molecules and biologics now focus on targets critical to ovarian carcinogenesis, metastasis, and immune surveillance. A number of these targets have been examined in phase I and II clinical trials with encouraging results, and while early data are limited, further investigation with single-agent or combination therapies may offer new hope to women with this lethal disease.

\section{Disclosure}

The authors report no conflicts of interest.

\section{References}

1. Jemal A, Siegel R, Ward E, et al. Cancer statistics, 2009. CA Cancer J Clin. 2009;59(4):225-249.

2. Cannistra SA. Cancer of the ovary. N Engl J Med. 2004;351(24): 2519-2529.

3. Gadducci A, Landoni F, Maggino T, et al. Serum CA125 assay at the time of relapse has no prognostic relevance in patients undergoing chemotherapy for recurrent ovarian cancer: a multicenter Italian study. Int J Gynecol Cancer. 1997;7(1):78-83.

4. Heintz AP, Odicino F, Maisonneuve P, et al. Carcinoma of the ovary. FIGO 6th Annual Report on the Results of Treatment in Gynecological Cancer. Int J Gynaecol Obstet. 2006;95(Suppl 1):S161-S192.

5. Thigpen JT, Blessing JA, Ball H, Hummel SJ, Barrett RJ. Phase II trial of paclitaxel in patients with progressive ovarian carcinoma after platinum-based chemotherapy: a Gynecologic Oncology Group study. J Clin Oncol. 1994;12(9):1748-1753.

6. Ushijima K. Treatment for recurrent ovarian cancer-at first relapse. J Oncol. 2010:497429.

7. Monk BJ, Coleman RL. Changing the paradigm in the treatment of platinum-sensitive recurrent ovarian cancer: from platinum doublets to nonplatinum doublets and adding antiangiogenesis compounds. Int J Gynecol Cancer. 2009;19(Suppl 2):S63-S67.

8. Gonzalez-Martin AJ, Calvo E, Bover I, et al. Randomized phase II trial of carboplatin versus paclitaxel and carboplatin in platinumsensitive recurrent advanced ovarian carcinoma: a GEICO (Grupo Espanol de Investigacion en Cancer de Ovario) study. Ann Oncol. 2005;16(5):749-755.

9. Pfisterer J, Plante M, Vergote I, et al. Gemcitabine plus carboplatin compared with carboplatin in patients with platinum-sensitive recurrent ovarian cancer: an intergroup trial of the AGO-OVAR, the NCIC CTG, and the EORTC GCG. J Clin Oncol. 2006;24(29): 4699-4707.

10. Alberts DS, Liu PY, Wilczynski SP, et al. Randomized trial of pegylated liposomal doxorubicin (PLD) plus carboplatin versus carboplatin in platinum-sensitive (PS) patients with recurrent epithelial ovarian or peritoneal carcinoma after failure of initial platinum-based chemotherapy (Southwest Oncology Group Protocol S0200). Gynecol Oncol. 2008;108(1):90-94.

11. Spriggs D. Optimal sequencing in the treatment of recurrent ovarian cancer. Gynecol Oncol. 2003;90(3 pt 2):S39-S44.

12. Markman M. Optimal management of recurrent ovarian cancer. Int $J$ Gynecol Cancer. 2009;19(Suppl 2):S40-S43.

13. Herzog TJ. Recurrent ovarian cancer: how important is it to treat to disease progression? Clin Cancer Res. 2004;10(22):7439-7449.

14. Cree IA, Kurbacher CM, Lamont A, Hindley AC, Love S. A prospective randomized controlled trial of tumour chemosensitivity assay directed chemotherapy versus physician's choice in patients with recurrent platinum-resistant ovarian cancer. Anticancer Drugs. 2007; 18(9):1093-1101.

15. Schrag D, Garewal HS, Burstein HJ, et al. American Society of Clinical Oncology Technology Assessment: chemotherapy sensitivity and resistance assays. J Clin Oncol. 2004;22(17):3631-3638.

16. Gordon AN, Granai CO, Rose PG, et al. Phase II study of liposomal doxorubicin in platinum- and paclitaxel-refractory epithelial ovarian cancer. J Clin Oncol. 2000;18(17):3093-3100. 
17. Muggia FM, Hainsworth JD, Jeffers S, et al. Phase II study of liposomal doxorubicin in refractory ovarian cancer: antitumor activity and toxicity modification by liposomal encapsulation. J Clin Oncol. 1997;15(3):987-993.

18. Monk BJ, Herzog TJ, Kaye SB, et al. Trabectedin plus pegylated liposomal Doxorubicin in recurrent ovarian cancer. J Clin Oncol. 2010; 28(19):3107-3114.

19. Havrilesky LJ, Alvarez AA, Sayer RA, et al. Weekly low-dose carboplatin and paclitaxel in the treatment of recurrent ovarian and peritoneal cancer. Gynecol Oncol. 2003;88(1):51-57.

20. Rose PG, Blessing JA, Ball HG, et al. A phase II study of docetaxel in paclitaxel-resistant ovarian and peritoneal carcinoma: a Gynecologic Oncology Group study. Gynecol Oncol. 2003;88(2):130-135.

21. Markman M, Webster K, Zanotti K, et al. Phase 2 trial of single-agent gemcitabine in platinum-paclitaxel refractory ovarian cancer. Gynecol Oncol. 2003;90(3):593-596.

22. Mutch DG, Orlando M, Goss T, et al. Randomized phase III trial of gemcitabine compared with pegylated liposomal doxorubicin in patients with platinum-resistant ovarian cancer. J Clin Oncol. 2007;25(19): 2811-2818.

23. Bookman MA, Malmstrom H, Bolis G, et al. Topotecan for the treatment of advanced epithelial ovarian cancer: an open-label phase II study in patients treated after prior chemotherapy that contained cisplatin or carboplatin and paclitaxel. J Clin Oncol. 1998;16(10): 3345-3352.

24. Safra T, Menczer J, Bernstein R, et al. Efficacy and toxicity of weekly topotecan in recurrent epithelial ovarian and primary peritoneal cancer. Gynecol Oncol. 2007;105(1):205-210.

25. Rose PG, Blessing JA, Mayer AR, Homesley HD. Prolonged oral etoposide as second-line therapy for platinum-resistant and platinumsensitive ovarian carcinoma: a Gynecologic Oncology Group study. J Clin Oncol. 1998;16(2):405-410.

26. Bodurka DC, Levenback C, Wolf JK, et al. Phase II trial of irinotecan in patients with metastatic epithelial ovarian cancer or peritoneal cancer. J Clin Oncol. 2003;21(2):291-297.

27. Sorensen P, Hoyer M, Jakobsen A, et al. Phase II study of vinorelbine in the treatment of platinum-resistant ovarian carcinoma. Gynecol Oncol. 2001;81(1):58-62.

28. Markman M, Hakes T, Reichman B, et al. Ifosfamide and mesna in previously treated advanced epithelial ovarian cancer: activity in platinum-resistant disease. J Clin Oncol. 1992;10(2):243-248.

29. Prefontaine M, Donovan JT, Powell JL, Buley L. Treatment of refractory ovarian cancer with 5-fluorouracil and leucovorin. Gynecol Oncol. 1996;61(2):249-252.

30. Kowalski RJ, Giannakakou P, Hamel E. Activities of the microtubulestabilizing agents epothilones A and B with purified tubulin and in cells resistant to paclitaxel (Taxol(R)). J Biol Chem. 1997;272(4): 2534-2541.

31. De Geest K, Blessing JA, Morris RT, et al. Phase II clinical trial of ixabepilone in patients with recurrent or persistent platinum- and taxaneresistant ovarian or primary peritoneal cancer: a gynecologic oncology group study. J Clin Oncol. 28(1):149-153.

32. Carter NJ, Keam SJ. Trabectedin: a review of its use in the management of soft tissue sarcoma and ovarian cancer. Drugs. 2007;67(15) 2257-2276.

33. Krasner CN, McMeekin DS, Chan S, et al. A Phase II study of trabectedin single agent in patients with recurrent ovarian cancer previously treated with platinum-based regimens. Br J Cancer. 2007;97(12): $1618-1624$.

34. Shih C, Chen VJ, Gossett LS, et al. LY231514, a pyrrolo[2,3-d]pyrimidine-based antifolate that inhibits multiple folate-requiring enzymes. Cancer Res. 1997;57(6):1116-11123.

35. Miller DS, Blessing JA, Krasner CN, et al. Phase II evaluation of pemetrexed in the treatment of recurrent or persistent platinum-resistant ovarian or primary peritoneal carcinoma: a study of the Gynecologic Oncology Group. J Clin Oncol. 2009;27(16):2686-2691.
36. Kamsteeg M, Rutherford T, Sapi E, et al. Phenoxodiol-an isoflavone analog-induces apoptosis in chemoresistant ovarian cancer cells. Oncogene. 2003;22(17):2611-2620.

37. Alvero AB, O'Malley D, Brown D, et al. Molecular mechanism of phenoxodiol-induced apoptosis in ovarian carcinoma cells. Cancer. 2006;106(3):599-608.

38. Fracasso PM, Blessing JA, Morgan MA, Sood AK, Hoffman JS. Phase II study of oxaliplatin in platinum-resistant and refractory ovarian cancer: a gynecologic group study. J Clin Oncol. 2003;21(15):2856-2859.

39. Pectasides D, Pectasides M, Farmakis D, et al. Oxaliplatin plus highdose leucovorin and 5-fluorouracil (FOLFOX 4) in platinum-resistant and taxane-pretreated ovarian cancer: a phase II study. Gynecol Oncol. 2004;95(1):165-172.

40. Faivre S, Kalla S, Cvitkovic E, et al. Oxaliplatin and paclitaxel combination in patients with platinum-pretreated ovarian carcinoma: an investigator-originated compassionate-use experience. Ann Oncol. 1999;10(9):1125-1128.

41. Recchia F, Saggio G, Amiconi G, et al. A multicenter phase II study of pegylated liposomal doxorubicin and oxaliplatin in recurrent ovarian cancer. Gynecol Oncol. 2007;106(1):164-169.

42. Germano D, Rosati G, Manzione L. Gemcitabine combined with oxaliplatin (GEMOX) as salvage treatment in elderly patients with advanced ovarian cancer refractory or resistant to platinum: a single institution experience. J Chemother. 2007;19(5):577-581.

43. Wosikowski K, Lamphere L, Unteregger G, et al. Preclinical antitumor activity of the oral platinum analog satraplatin. Cancer Chemother Pharmacol. 2007;60(4):589-600.

44. Steinman RM. Dendritic cells: understanding immunogenicity. Eur $J$ Immunol. 2007;37(Suppl 1):S53-S60.

45. Zhang L, Conejo-Garcia JR, Katsaros D, et al. Intratumoral T cells, recurrence, and survival in epithelial ovarian cancer. $N$ Engl $J$ Med. 2003;348(3):203-213.

46. Sato E, Olson SH, Ahn J, et al. Intraepithelial CD8+ tumor-infiltrating lymphocytes and a high $\mathrm{CD} 8+$ /regulatory $\mathrm{T}$ cell ratio are associated with favorable prognosis in ovarian cancer. Proc Natl Acad Sci U SA. 2005;102(51):18538-18543

47. Curiel TJ, Coukos G, Zou L, et al. Specific recruitment of regulatory $\mathrm{T}$ cells in ovarian carcinoma fosters immune privilege and predicts reduced survival. Nat Med. 2004;10(9):942-949.

48. Liu B, Nash J, Runowicz C, et al. Ovarian cancer immunotherapy: opportunities, progresses and challenges. J Hematol Oncol. 2010;3:7.

49. Cheever MA, Allison JP, Ferris AS, et al. The prioritization of cancer antigens: a national cancer institute pilot project for the acceleration of translational research. Clin Cancer Res. 2009;15(17):5323-5337.

50. Hird V, Maraveyas A, Snook D, et al. Adjuvant therapy of ovarian cancer with radioactive monoclonal antibody. Br J Cancer. 1993;68(2): 403-406.

51. Nicholson S, Bomphray CC, Thomas H, et al. A phase I trial of idiotypic vaccination with HMFG1 in ovarian cancer. Cancer Immunol Immunother. 2004;53(9):809-816.

52. Oei AL, Verheijen RH, Seiden MV, et al. Decreased intraperitoneal disease recurrence in epithelial ovarian cancer patients receiving intraperitoneal consolidation treatment with yttrium-90-labeled murine HMFG1 without improvement in overall survival. Int J Cancer. 2007; 120(12):2710-2714.

53. Ehlen TG, Hoskins PJ, Miller D, et al. A pilot phase 2 study of oregovomab murine monoclonal antibody to CA125 as an immunotherapeutic agent for recurrent ovarian cancer. Int J Gynecol Cancer. 2005;15(6): $1023-1034$.

54. Gordon AN, Schultes BC, Gallion H, et al. CA125- and tumor-specific T-cell responses correlate with prolonged survival in oregovomabtreated recurrent ovarian cancer patients. Gynecol Oncol. 2004;94(2): 340-351.

55. Pfisterer J, du Bois A, Sehouli J, et al. The anti-idiotypic antibody abagovomab in patients with recurrent ovarian cancer. A phase I trial of the AGO-OVAR. Ann Oncol. 2006;17(10):1568-1577. 
56. Reinartz S, Kohler S, Schlebusch H, et al. Vaccination of patients with advanced ovarian carcinoma with the anti-idiotype ACA125: immunological response and survival (phase Ib/II). Clin Cancer Res. 2004;10(5):1580-1587.

57. Sabbatini P, Dupont J, Aghajanian C, et al. Phase I study of abagovomab in patients with epithelial ovarian, fallopian tube, or primary peritoneal cancer. Clin Cancer Res. 2006;12(18):5503-5510.

58. Connor J, Bannerji R, Saito S, et al. Regression of bladder tumors in mice treated with interleukin 2 gene-modified tumor cells. J Exp Med. 1993;177(4):1127-1134.

59. Vlad AM, Budiu RA, Lenzner DE, et al. A phase II trial of intraperitoneal interleukin-2 in patients with platinum-resistant or platinumrefractory ovarian cancer. Cancer Immunol Immunother. 2009. [Epub ahead of print].

60. Roche MR, Rudd PJ, Krasner CN, et al. Phase II trial of GM-CSF in women with asymptomatic recurrent mullerian tumors. Gynecol Oncol. 2010;116(2):168-172.

61. Schmeler KM, Vadhan-Raj S, Ramirez PT, et al. A phase II study of GM-CSF and rIFN-gammalb plus carboplatin for the treatment of recurrent, platinum-sensitive ovarian, fallopian tube and primary peritoneal cancer. Gynecol Oncol. 2009;113(2):210-215.

62. Kaur T, Slavcev RA, Wettig SD. Addressing the challenge: current and future directions in ovarian cancer therapy. Curr Gene Ther. 2009;9(6):434-458.

63. Qian HN, Liu GZ, Cao SJ, Feng J, Ye X. The experimental study of ovarian carcinoma vaccine modified by human B7-1 and IFN-gamma genes. Int J Gynecol Cancer. 2002;12(1):80-85.

64. Kantoff PW, Higano CS, Shore ND, et al; IMPACT Study Investigators. Sipuleucel-T immunotherapy for castration-resistant prostate cancer. N Engl J Med. 2010;363(5):411-422.

65. Cannon MJ, O’Brien TJ. Cellular immunotherapy for ovarian cancer. Expert Opin Biol Ther. 2009;9(6):677-88.

66. Brossart P, Wirths S, Stuhler G, et al. Induction of cytotoxic T-lymphocyte responses in vivo after vaccinations with peptide-pulsed dendritic cells. Blood. 2000;96(9):3102-3108.

67. Hernando JJ, Park TW, Kubler K, et al. Vaccination with autologous tumour antigen-pulsed dendritic cells in advanced gynaecological malignancies: clinical and immunological evaluation of a phase I trial. Cancer Immunol Immunother. 2002;51(1):45-52.

68. Rosenberg SA, Restifo NP, Yang JC, Morgan RA, Dudley ME. Adoptive cell transfer: a clinical path to effective cancer immunotherapy. Nat Rev Cancer. 2008;8(4):299-308.

69. Dudley ME, Wunderlich JR, Yang JC, et al. Adoptive cell transfer therapy following non-myeloablative but lymphodepleting chemotherapy for the treatment of patients with refractory metastatic melanoma. J Clin Oncol. 2005;23(10):2346-2357.

70. Aoki Y, Takakuwa K, Kodama S, et al. Use of adoptive transfer of tumor-infiltrating lymphocytes alone or in combination with cisplatincontaining chemotherapy in patients with epithelial ovarian cancer. Cancer Res. 1991;51(7):1934-1939.

71. Carpenito C, Milone MC, Hassan R, et al. Control of large, established tumor xenografts with genetically retargeted human $\mathrm{T}$ cells containing CD28 and CD137 domains. Proc Natl Acad Sci U S A. 2009;106(9): 3360-3365.

72. Kershaw MH, Westwood JA, Parker LL, et al. A phase I study on adoptive immunotherapy using gene-modified $\mathrm{T}$ cells for ovarian cancer. Clin Cancer Res. 2006;12(20 pt 1):6106-6115.

73. Hodi FS, Butler M, Oble DA, et al. Immunologic and clinical effects of antibody blockade of cytotoxic $\mathrm{T}$ lymphocyte-associated antigen 4 in previously vaccinated cancer patients. Proc Natl Acad Sci U SA. 2008;105(8):3005-3010.

74. Barnett B, Kryczek I, Cheng P, Zou W, Curiel TJ. Regulatory T cells in ovarian cancer: biology and therapeutic potential. Am J Reprod Immunol. 2005;54(6):369-377.

75. Markman M. Antiangiogenic drugs in ovarian cancer. Expert Opin Pharmacother. 2009;10(14):2269-2277.
76. Abu-Jawdeh GM, Faix JD, Niloff J, et al. Strong expression of vascular permeability factor (vascular endothelial growth factor) and its receptors in ovarian borderline and malignant neoplasms. Lab Invest. 1996; 74(6):1105-1115.

77. Cooper BC, Ritchie JM, Broghammer CL, et al. Preoperative serum vascular endothelial growth factor levels: significance in ovarian cancer. Clin Cancer Res. 2002;8(10):3193-3197.

78. Raspollini MR, Amunni G, Villanucci A, et al. Prognostic significance of microvessel density and vascular endothelial growth factor expression in advanced ovarian serous carcinoma. Int J Gynecol Cancer. 2004; 14(5):815-823.

79. Burger RA, Sill MW, Monk BJ, Greer BE, Sorosky JI. Phase II trial of bevacizumab in persistent or recurrent epithelial ovarian cancer or primary peritoneal cancer: a Gynecologic Oncology Group Study. J Clin Oncol. 2007;25(33):5165-5171.

80. Cannistra SA, Matulonis UA, Penson RT, et al. Phase II study of bevacizumab in patients with platinum-resistant ovarian cancer or peritoneal serous cancer. J Clin Oncol. 2007;25(33): $5180-5186$.

81. Cheng X, Moroney JW, Levenback CF, et al. What is the benefit of bevacizumab combined with chemotherapy in patients with recurrent ovarian, fallopian tube or primary peritoneal malignancies? J Chemother. 2009;21(5):566-572.

82. Garcia AA, Hirte H, Fleming G, et al. Phase II clinical trial of bevacizumab and low-dose metronomic oral cyclophosphamide in recurrent ovarian cancer: a trial of the California, Chicago, and Princess Margaret Hospital phase II consortia. J Clin Oncol. 2008; 26(1):76-82.

83. Camidge DR, Eckhardt SG, Diab S, et al. A phase I dose-escalation study of weekly IMC-1121B. a fully human anti-vascular endothelial growth factor receptor 2 (VEGFR2) IgG1 monoclonal antibody (Mab), in patients (pts) with advanced cancer. $J$ Clin Oncol. 2006;24(185 (June 20 Suppl)):3032.

84. A Phase 2, Non-randomized, Open-label, Multicenter Study of IMC1121B in the Treatment of Persistent or Recurrent Epithelial Ovarian, Fallopian Tube, or Primary Peritoneal Carcinoma. Accessed 2010 Aug 11. http://clinicaltrials.gov/ct2/show/NCT00721162.

85. Ledermann JA, Raja FA. Targeted trials in ovarian cancer. Gynecol Oncol. 2010;119(1):151-156.

86. Tew W, Colombo N, Ray-Caquard I, et al. VEGF-Trap for patients with recurrent platinum resistant epithelial ovarian cancer. J Clin Oncol. 2008;25(18S):Abstract 14598.

87. Wedge SR, Kendrew J, Hennequin LF, et al. AZD2171: a highly potent, orally bioavailable, vascular endothelial growth factor receptor-2 tyrosine kinase inhibitor for the treatment of cancer. Cancer Res. 2005; 65(10):4389-4400.

88. Herbst RS, Shin DM. Monoclonal antibodies to target epidermal growth factor receptor-positive tumors: a new paradigm for cancer therapy. Cancer. 2002;94(5):1593-1611.

89. Lafky JM, Wilken JA, Baron AT, Maihle NJ. Clinical implications of the ErbB/epidermal growth factor (EGF) receptor family and its ligands in ovarian cancer. Biochim Biophys Acta. 2008;1785(2): 232-265.

90. Schilder RJ, Pathak HB, Lokshin AE, et al. Phase II trial of single agent cetuximab in patients with persistent or recurrent epithelial ovarian or primary peritoneal carcinoma with the potential for dose escalation to rash. Gynecol Oncol. 2009;113(1):21-27.

91. Wu M, Rivkin A, Pham T. Panitumumab: human monoclonal antibody against epidermal growth factor receptors for the treatment of metastatic colorectal cancer. Clin Ther. 2008;30(1):14-30.

92. Smith I, Procter M, Gelber RD, et al. 2-year follow-up of trastuzumab after adjuvant chemotherapy in HER2-positive breast cancer: a randomised controlled trial. Lancet. 2007;369(9555):29-36.

93. Slamon DJ, Godolphin W, Jones LA, et al. Studies of the HER-2/ neu proto-oncogene in human breast and ovarian cancer. Science. 1989; 244(4905):707-712. 
94. Bookman MA, Darcy KM, Clarke-Pearson D, Boothby RA, Horowitz IR. Evaluation of monoclonal humanized anti-HER2 antibody, trastuzumab, in patients with recurrent or refractory ovarian or primary peritoneal carcinoma with overexpression of HER2: a phase II trial of the Gynecologic Oncology Group. J Clin Oncol. 2003;21(2):283-290.

95. Makhija S, Amler LC, Glenn D, et al. Clinical activity of gemcitabine plus pertuzumab in platinum-resistant ovarian cancer, fallopian tube cancer, or primary peritoneal cancer. J Clin Oncol. 28(7): $1215-1223$

96. Schilder RJ, Sill MW, Chen X, et al. Phase II study of gefitinib in patients with relapsed or persistent ovarian or primary peritoneal carcinoma and evaluation of epidermal growth factor receptor mutations and immunohistochemical expression: a Gynecologic Oncology Group Study. Clin Cancer Res. 2005;11(15):5539-5548.

97. Posadas EM, Liel MS, Kwitkowski V, et al. A phase II and pharmacodynamic study of gefitinib in patients with refractory or recurrent epithelial ovarian cancer. Cancer. 2007;109(7):1323-1330.

98. Hirte H, Oza A, Swenerton K, et al. A phase II study of erlotinib (OSI-774) given in combination with carboplatin in patients with recurrent epithelial ovarian cancer (NCIC CTG IND.149). Gynecol Oncol. 118(3):308-312.

99. Apte SM, Bucana CD, Killion JJ, Gershenson DM, Fidler IJ. Expression of platelet-derived growth factor and activated receptor in clinical specimens of epithelial ovarian cancer and ovarian carcinoma cell lines. Gynecol Oncol. 2004;93(1):78-86.

100. Schilder RJ, Sill MW, Lee RB, et al. Phase II evaluation of imatinib mesylate in the treatment of recurrent or persistent epithelial ovarian or primary peritoneal carcinoma: a Gynecologic Oncology Group Study. J Clin Oncol. 2008;26(20):3418-3425.

101. Coleman RL, Broaddus RR, Bodurka DC, et al. Phase II trial of imatinib mesylate in patients with recurrent platinum- and taxaneresistant epithelial ovarian and primary peritoneal cancers. Gynecol Oncol. 2006;101(1):126-131.

102. Biagi JJ, Oza AM, Chalchal HI, et al. A phase II study of sunitinib in patients with recurrent epithelial ovarian and primary peritoneal carcinoma: an NCIC Clinical Trials Group Study. Ann Oncol. 2010. [Epub ahead of print].

103. Friedlander M, Hancock KC, Rischin D, et al. A Phase II, open-label study evaluating pazopanib in patients with recurrent ovarian cancer. Gynecol Oncol. 2010;119(1):32-37.

104. Kalli KR. MORAb-003, a fully humanized monoclonal antibody against the folate receptor alpha, for the potential treatment of epithelial ovarian cancer. Curr Opin Investig Drugs. 2007;8(12):1067-1073.

105. Weitman SD, Lark RH, Coney LR, et al. Distribution of the folate receptor GP38 in normal and malignant cell lines and tissues. Cancer Res. 1992;52(12):3396-3401.

106. Chung MK, Han SS, Roh JK. Synergistic embryotoxicity of combination pyrimethamine and folic acid in rats. Reprod Toxicol. 1993;7(5): 463-468.

107. Molthoff CF, Prinssen HM, Kenemans P, et al. Escalating protein doses of chimeric monoclonal antibody MOv18 immunoglobulin G in ovarian carcinoma patients: a phase I study. Cancer. 1997;80 (Suppl 12):2712-2720.

108. Van Zanten-Przybysz I, Molthoff C, Gebbinck JK, et al. Cellular and humoral responses after multiple injections of unconjugated chimeric monoclonal antibody MOv18 in ovarian cancer patients: a pilot study. J Cancer Res Clin Oncol. 2002;128(9):484-492.

109. Coliva A, Zacchetti A, Luison E, et al. 90Y Labeling of monoclonal antibody MOv18 and preclinical validation for radioimmunotherapy of human ovarian carcinomas. Cancer Immunol Immunother. 2005; 54(12):1200-1213.

110. Zacchetti A, Coliva A, Luison E, et al. (177)Lu- labeled MOv18 as compared to (131)I- or (90)Y-labeled MOv18 has the better therapeutic effect in eradication of alpha folate receptor-expressing tumor xenografts. Nucl Med Biol. 2009;36(7):759-770.
111. Ebel W, Routhier EL, Foley B, et al. Preclinical evaluation of MORAb-003, a humanized monoclonal antibody antagonizing folate receptor-alpha. Cancer Immun. 2007;7:6.

112. Ahmed S, Gerst S, Vander Els N, Pezzuli S, Sabbatini P, Hensley M, Dupont J, et al. Phase I Study of MORAb-003, a humanized anti-folate receptor-alpha, monoclonal antibody, in platinum resistant ovarian cancer. Proc Am Soc Clin Oncol. 2006;25:Abstract \# 5027.

113. Philips M, Armstrong D, Coleman R, et al. Novel phase II study design of MORAb-003, a monoclonal antibody against folate receptor alpha in platinum-sensitive ovarian cancer in first relapse. Proc Am Soc Clinc Oncol. 2007;43:Abstract \# 5583.

114. Went PT, Lugli A, Meier S, et al. Frequent EpCam protein expression in human carcinomas. Hum Pathol. 2004;35(1):122-128.

115. Bellone S, Siegel ER, Cocco E, et al. Overexpression of epithelial cell adhesion molecule in primary, metastatic, and recurrent/chemotherapyresistant epithelial ovarian cancer: implications for epithelial cell adhesion molecule-specific immunotherapy. Int J Gynecol Cancer. 2009;19(5):860-866.

116. Ruf P, Lindhofer H. Induction of a long-lasting antitumor immunity by a trifunctional bispecific antibody. Blood. 2001;98(8):2526-2534.

117. Heiss MM, Murawa P, Koralewski P, et al. The trifunctional antibody catumaxomab for the treatment of malignant ascites due to epithelial cancer: Results of a prospective randomized phase II/III trial. Int $J$ Cancer. 2010;127(9):2209-2221.

118. Hassan R, Bullock S, Premkumar A, et al. Phase I study of SS1P, a recombinant anti-mesothelin immunotoxin given as a bolus I.V. infusion to patients with mesothelin-expressing mesothelioma, ovarian, and pancreatic cancers. Clin Cancer Res. 2007;13(17):5144-5149.

119. Oral contraceptive use and the risk of ovarian cancer. The Centers for Disease Control Cancer and Steroid Hormone Study. JAMA. 1983; 249(12):1596-1599.

120. O’Donnell AJ, Macleod KG, Burns DJ, Smyth JF, Langdon SP. Estrogen receptor-alpha mediates gene expression changes and growth response in ovarian cancer cells exposed to estrogen. Endocr Relat Cancer. 2005;12(4):851-866.

121. Williams CJ. Tamoxifen for relapse of ovarian cancer. Cochrane Database Syst Rev. 2001(1):CD001034.

122. Ramirez PT, Schmeler KM, Milam MR, et al. Efficacy of letrozole in the treatment of recurrent platinum- and taxane-resistant high-grade cancer of the ovary or peritoneum. Gynecol Oncol. 2008;110(1): $56-59$.

123. Smyth JF, Gourley C, Walker G, et al. Antiestrogen therapy is active in selected ovarian cancer cases: the use of letrozole in estrogen receptorpositive patients. Clin Cancer Res. 2007;13(12):3617-3622.

124. Argenta PA, Thomas SG, Judson PL, et al. A phase II study of fulvestrant in the treatment of multiply-recurrent epithelial ovarian cancer. Gynecol Oncol. 2009;113(2):205-209.

125. Rocereto TF, Brady WE, Shahin MS, et al. A phase II evaluation of mifepristone in the treatment of recurrent or persistent epithelial ovarian, fallopian or primary peritoneal cancer: a gynecologic oncology group study. Gynecol Oncol. 2010;16(3):332-334.

126. Balbi G, Piano LD, Cardone A, Cirelli G. Second-line therapy of advanced ovarian cancer with GnRH analogs. Int J Gynecol Cancer. 2004;14(5):799-803.

127. Hasan J, Ton N, Mullamitha S, et al. Phase II trial of tamoxifen and goserelin in recurrent epithelial ovarian cancer. Br J Cancer. 2005; 93(6):647-651.

128. Verschraegen CF, Westphalen S, Hu W, et al. Phase II study of cetrorelix, a luteinizing hormone-releasing hormone antagonist in patients with platinum-resistant ovarian cancer. Gynecol Oncol. 2003;90(3): 552-559.

129. D'Andrea AD, Grompe M. The Fanconi anaemia/BRCA pathway. Nat Rev Cancer. 2003;3(1):23-34.

130. Pal T, Permuth-Wey J, Betts JA, et al. BRCA1 and BRCA2 mutations account for a large proportion of ovarian carcinoma cases. Cancer. 2005;104(12):2807-2816. 
131. McCabe N, Turner NC, Lord CJ, et al. Deficiency in the repair of DNA damage by homologous recombination and sensitivity to poly(ADP-ribose) polymerase inhibition. Cancer Res. 2006;66(16): 8109-8115.

132. Konstantinopoulos PA, Spentzos D, Karlan BY, et al. Gene expression profile of BRCAness that correlates with responsiveness to chemotherapy and with outcome in patients with epithelial ovarian cancer. J Clin Oncol. 2010;28(22):3555-3561.
133. Audeh MW, Carmichael J, Penson RT, et al. Oral poly(ADP-ribose) polymerase inhibitor olaparib in patients with BRCA1 or BRCA2 mutations and recurrent ovarian cancer: a proof-of-concept trial. Lancet. 2010;376(9737):245-251.

\section{Publish your work in this journal}

Cancer Management and Research is an international, peer-reviewed open access journal focusing on cancer research and the optimal use of preventative and integrated treatment interventions to achieve improved outcomes, enhanced survival and quality of life for the cancer patient. The journal welcomes original research, clinical \& epidemiological studies, reviews \& evaluations, guidelines, expert opinion \& commentary, case reports \& extended reports. The manuscript management system is completely online and includes a very quick and fair peerreview system, which is all easy to use. Visit http://www.dovepress.com/ testimonials.php to read real quotes from published authors. 